\title{
Histopathology of Appendicectomy Specimen: A 5 Year Hospital Based Study
}

\author{
Authors \\ Dr Bharti Devi Thaker ${ }^{1}$, Dr Deepti Gupta ${ }^{2}$, Dr Kailash Singh ${ }^{3}$ \\ ${ }^{1,2}$ Demonstrator, Department of Pathology GMC Jammu \\ ${ }^{3}$ Assistant Professor, Department of Surgery, GMC Jammu \\ Corresponding Author \\ Dr Bharti Devi Thaker \\ Mobile No.9419796784, Email: bharti68@gmail.com
}

\begin{abstract}
Introduction: Appendix is a tube like organ that sits at the junction of small intestine and large intestine and its function is unknown. Appendicectomy is most commonly performed for acute appendicitis. This study was conducted over a period of 2 years retrospectively to study the the pattern of lesions (non neoplastic and neoplastic) in the appendecetomy specimen.

Result: Out of 550 appendicectomy specimen received during the study period, 545 cases (99\%) were found to be involved by non neoplastic lesions and only 5 cases (1\%) were neoplastic. The cases age ranged from 4 years to 80 years with mean age of 34 years. Male cases (71.6\%) were more as compared to female cases (28.3\%). Most common histopathological spectrum seen was Acute appendicitis (65.4\% ) followed by Acute appendicitis with periappendicitis (25.4\%), Early acute appendicitis (4\%), Vermiform appendix (2.5\%), Chronic fibrosing appendicitis(1.6\%), carcinoid (4 cases) and mucinous cystadenoma (1cases). The most common clinical presentation was pain right iliac fossa (76\%).

Conclusion: Appendicitis is the most common histopathological diagnosisi. Maximum number of cases are seen in the $2^{\text {nd }}$ to $4^{\text {th }}$ decade. Pain in the right iliac fossa is the most common presenting symptom.

Keywords- Appendix, Appendicitis, Appendicectomy.
\end{abstract}

\section{Introduction}

Appendix is a tube like organ that sits at the junction of small intestine and large intestine and its function is unknown. Appendicectomy is most commonly performed for acute appendicitis. Acute appendicitis is the most common disease of surgical field in worldwide and affects about 7 percent of the population ${ }^{(1)}$. Surgeons have many challenges for diagnosis of it, yet. Diagnosis of acute appendicitis is made primarily on basis of history and physical examination, with additional assistance from laboratory and radiographic findings ${ }^{(2)}$. However histopathologic examination is the gold standard for the diagnosis of acute appendicitis ${ }^{(3)}$. Appendiceal tumours are unusual accounting for $0.4 \%$ of all gastrointestinal tract malignancies. An estimated $1 \%$ of all appendecectomy specimens contain a neoplasm ${ }^{(4)}$. Not only has the pathologic diagnosis of acute inflammation, at times unusual findings such as 


\section{JMSCR Vol||05||Issue ||06||Page 23773-23776||June}

incidental tumours highlights the importance of pathologic analysis of every single resected appendix.

\section{Aim}

To study the pattern of lesions (non neoplastic and neoplastic) in the appendecetomy specimen.

\section{Material and Methods}

It was a 2 year study done retrospectively from may 2015 to April 2017. It was conducted in histopathology section of pathology department of GMC Jammu. Histopathological records of resected appendices were reviewed from records. All specimen were fixed in $10 \%$ buffered formalin. A detailed gross examination of appendecectomy specimen were carried out. Sections were taken for histology. These included two transverse bits, one from resected end and another from body region and one longitudinal bit from the tip. Histology slides of all cases were reviewed. Staining was done by Haematoxylin and Eosin staining procedure ${ }^{(5)}$.

\section{Result}

A total of 550 specimen were received during the study period. Specimen received included laproscopic and open appendicectomy specimen. This constituted $7.6 \%$ of total number of surgical specimen (7200) received during the study period. The cases age ranged from 4 years to 80 years with mean age of 34 years. Maximum number of cases were seen uptil 40 years (456) of age .Peak age icidence was seen between 21 to 40 years with 247 cases recorded.

A greater percentage of appendicectomies were performed in males (71.6\%) as compared to females $(28.3 \%)$. Male to Female ratio being 2.5:1.

In this study of 550 appendicectomy specimen, 545 cases (99\%) including 14 normal cases were found to be involved by non neoplastic lesions and only 5 cases (1\%) were involved by neoplastic lesion. Both neoplastic and non neoplastic cases were found to be more common in males as compared to females.

Most common histopathological spectrum seen was Acute appendicitis (65.4\%). Other lesion were Acute appendicitis with periappendicitis (25.4\%) followed by Early acute appendicitis (4\%), Vermiform appendix (2.5\%), Chronic fibrosing appendicitis (1.6\%). Among the neoplastic lesion carcinoid (4 cases) followed by mucinous cystadenoma (1 cases) were seen.

The most common clinical presentation was pain right iliac fossa $(76 \%)$. Other presentation were generalized pain abdomen (12\%), fever and vomiting $(8 \%)$.

Table 1 Age wise distribution of the lesion.

\begin{tabular}{|l|c|c|c|c|c|c|c|}
\hline Age & $\begin{array}{c}\text { Acute } \\
\text { appendicitis }\end{array}$ & $\begin{array}{c}\text { AA with } \\
\text { Periappendicitis }\end{array}$ & $\begin{array}{c}\text { Early Acute } \\
\text { Appendicitis }\end{array}$ & $\begin{array}{c}\text { Vermiform } \\
\text { appendix }\end{array}$ & $\begin{array}{c}\text { Chronic } \\
\text { fibrosing } \\
\text { Appendicitis }\end{array}$ & Carcinoid & $\begin{array}{c}\text { Mucinous } \\
\text { Cystadenoma }\end{array}$ \\
\hline $0-20$ & 135 & 50 & 12 & 8 & 4 & - & - \\
\hline $21-40$ & 159 & 70 & 10 & 2 & 3 & 2 & 1 \\
\hline $41-60$ & 54 & 18 & - & 2 & 2 & 2 & - \\
\hline$>61$ & 12 & 2 & - & 2 & - & - & - \\
\hline Total & 360 & 140 & 22 & 14 & 9 & 4 & 1 \\
\hline
\end{tabular}

Table 2 Distribution of Appendicectomy specimen as per their nature

\section{Discussion \\ In our study, cases age ranged from 4 years to 80}

\begin{tabular}{|l|c|c|}
\hline Lesion & No. of cases $(\mathrm{n}=550)$ & Percentage (\%) \\
\hline Non Neoplastic & 545 & 99 \\
\hline Neoplastic Lesion & 5 & 1 \\
\hline Total & 550 & 100 \\
\hline
\end{tabular}
years with mean age of 34 years. Maximum number of cases were seen uptil 40 years of age. Similar to that seen in study done by Shrestha et al (6). Maximum number of cases who went 
appendicectomies were between 21 to 40 years (44.9\%) age group . Similar findings were seen in study done by Marudanayagam et al ${ }^{(7)}$ wherein most appendicectomies $(64.58 \%)$ were performed in the second decade of life. Sinha RTK et al ${ }^{(8)}$ also found peak age incidence between 21 to 40 years.

A greater percentage of appendicectomies were performed in males $(71.6 \%)$ as compared to females $(28.3 \%)$. Male to Female ratio being 2.5:1.These findings were in concordance with those of Nabipour et al ${ }^{(1)}$ and Makaju et al ${ }^{(9)}$. Chawla H.K.et al ${ }^{(10)}$ in his study found $(60.95 \%)$ male cases and $(39.05 \%)$ female cases similar to our study. However Shrestha et al (6) showed higher female preponderance with a Male to Female ratio of 1:1.12.

Out of 550 appendicectomy specimen, 545 cases (99 \%) including 14 normal cases were found to be involved by non neoplastic lesions and only 5 cases $(1 \%)$ were involved by neoplastic lesion. Similar to study done by Ayub $\mathrm{M}$ et al ${ }^{(11)}$. Kulkarni MP et $\mathrm{al}^{(12)}$ found non neoplastic lesion (99.34\%) to be more common as compared to neoplastic lesion $(0.64 \%)$.

Both neoplastic and non neoplastic cases were found to be more common in males as compared to females similar to that found by Zulfikar et al ${ }^{(13)}$ in his study.

Most common histopathological spectrum seen was Acute appendicitis (65.4\%). Similar to that seen in studies done by Chawda HK et al ${ }^{(10)}$ and Nikhumb D B et al ${ }^{(14)}$.

Second most common lesion was Acute appendicitis with periappendicitis (25.4\%) for which appendicectomy was done. Similar to study done by Sharma $S$ et al ${ }^{(4)}$.

It was followed by Early acute appendicitis (4\%), Vermiform appendix (2.5\%), Chronic fibrosing appendicitis (1.6\%). Among the neoplastic lesion carcinoid (4 cases) followed by mucinous cystadenoma (1 case) were seen .Sharma $\mathrm{S}$ et al ${ }^{(4)}$ found similar pattern in her study.

The most common clinical presentation was pain right iliac fossa $(76 \%)$. Other presentation were generalized pain abdomen (12\%), fever and vomiting (8\%). Similar findings were seen in the study done by Edino et al ${ }^{(15)}$.

\section{Conclusion}

Appendicitis is the most common histopathological diagnosisi. Maximum number of cases are seen in the $2^{\text {nd }}$ to $4^{\text {th }}$ decade. Pain in the right iliac fossa is the most common presenting symptom. Histopathology remains the gold standard to confirm the diagnosis of various lesions for which appendicectomy is done.

\section{References}

1. Nabipour F; Histopathological feature of acute appendicitis in Kerman,Iran from 1997 to 2003.Am J Environ Sci,2005;1 (2):130-132.

2. Lally K.P, C.S.Cox and R.J.Andrassy, 2004. Appendix, In:Townsend, C.M., R.D.Beauchamp, B. M.Evers and K.L.Mattox,Sabiston textbook of Surgery, $17^{\text {th }}$ Edn. Elsevier Saunders Co., Philadelphia, pp:1381-1400.

3. Rosai J.,2004.Rosai and Akerman Surgical pathology, $9^{\text {th }}$ Edn., Mosby Co.,China ,pp: 757-761.

4. Sharma S, Mahajan M, Rasool $M$ et al. Histopathology of Appendicectomy specimen:A 5 year study. Sch. J. App.Med.Sci.,2014;2(1B):176-180.

5. Wilson I, Gamble M;The Hematoxylins and Eosins:In Bancroft JD, Gamble M editors; Theory and practice of Histological Techniques $\quad, 5^{\text {th }} \quad$ edition,Churchill Livingston 2002:325-344.

6. Shrestha R,Ranabhat SR, Tiwari M. Histopathological analysis of appendicectomy specimens. Journal of pathology of Nepal(2012) Vol.2,215-219.

7. Marudanayagam R, Williams GT, Rees BI; Review of Pathological results of 2660 appendecectomy specimens Gastro., 2006;41(8):745-749. 
8. Sinha RTK, Dey A. A retrospective study of histopathological features of Appendecectomy specimens-What all can expect. J Med. Sci\& Health.2016 ,2(2):6-12.

9. Makaju R, Mohammad A, Shakyl A; Acute appendicitis: Analysis of 518 histopathologically diagnosis cases in the Kathmandu University Hospital,Nepal. Kathmandu Univ Med J.,2010;8(2):227230.

10. Chawda HK, Miskin AT, Dombale VD. Spectrum of Histopathological lesion in surgically removed appendix. J Drug Discovery and Therapeutics, 2015;3(28):56-59.

11. Ayub M,Al- Swailmi FK, Mehmood Y et al. Histopathological examination of appendicectomy specimens at district hospital of Saudi Arabia,2015;31(4).

12. Kulkarni MP, Sulhyan KR, Barodawala SM et al. Histopathological study of lesions of appendix. Intl.J of Health Sci.\& Res.2017.1(4):90-95.

13. Zulfikar I, Khanzada TW, Sushel C et al. Review of the pathologic diagnosis of appendecectomy specimens. Annals of King Edward Medical University, 2009; 15(4):168-170.

14. Nikumbh DB, Thakur RY, Singhavi S et al. Histopathological analysis of unusual findings in appendicectomy specimens: A retrospective study and literature review. Annals of pathology and Laboratory Medicine,2016 Vol.03,No.03,224 -229.

15. Edino ST, Mohammed AZ, Ochicha O et al.A ppendicitis in Kano, Nigeria: A 5 year review of pattern, morbidity and mortality. Annals of African Medicine ,2004;3(1):3841. 